\title{
Developing a strawberry yogurt fortified with marine fish oil ${ }^{1}$
}

\author{
J. D. Estrada, ${ }^{\star}$ C. Boeneke,† P. Bechtel, $\neq$ and S. Sathivel ${ }^{\star} \S^{2}$ \\ *Department of Food Science, and \\ †School of Animal Sciences, Louisiana State University Agricultural Center, Baton Rouge 70803 \\ ‡USDA ARS, Subarctic Research Unit, University of Alaska-Fairbanks, Kodiak 99615 \\ §Department of Biological and Agricultural Engineering, Louisiana State University Agricultural Center, Baton Rouge 70803
}

\section{ABSTRACT}

Fortified dairy products appeal to a wide variety of consumers and have the potential to increase sales in the yogurt industry and help increase intake of longchain n-3 fatty acids. The objectives of this study were to develop a strawberry yogurt containing microencapsulated salmon oil (MSO; $2 \% \mathrm{wt} / \mathrm{vol}$ ) and evaluate its characteristics during 1 mo of storage. Unpurified salmon oil (USO) was purified (PSO) and both USO and PSO were analyzed for peroxide value (PV), anisidine value $(\mathrm{AV})$, total oxidation, free fatty acids (FFA), and moisture content. A stable emulsion was prepared with $7 \%$ PSO, $22 \%$ gum arabic, $11 \%$ maltodextrin, and $60 \%$ water. The emulsion was spray-dried to produce MSO. The MSO was added to strawberryflavored yogurt (SYMSO) before pasteurization and homogenization, and a control (SY) without MSO was produced. Both yogurts were stored for $1 \mathrm{mo}$ at $4^{\circ} \mathrm{C}$ and we determined the quality characteristics including acidity $(\mathrm{pH})$, syneresis, thiobarbituric acid (TBA), fatty acid methyl ester composition, color, and lactic acid bacteria (LAB) count. The entire experiment was replicated 3 times. Total oxidation (unitless) of USO, PSO, and MSO was calculated to be $20.7 \pm 1.26$, $10.9 \pm 0.1$, and $13.4 \pm 0.25$, respectively. Free fatty acid contents were $1.61 \pm 0.19 \%, 0.59 \pm 0.02 \%$, and $0.77 \pm 0.02 \%$ for USO, PSO, and MSO, respectively. Eicosapentaenoic acid and docosahexaenoic acid were the predominant polyunsaturated fatty acids in MSO and in SYMSO, but neither was detected in SY. Fortification of SY with MSO had no significant effect on yogurt $\mathrm{pH}$ or syneresis. A decrease in concentration of lactic acid bacteria was observed during the storage of all yogurts. Thiobarbituric acid values significantly increased as storage time increased and SY had a significantly lighter (higher $\mathrm{L}^{*}$ ) and less yellow (lower $\mathrm{b}^{*}$ )

\footnotetext{
Received January 31, 2011.

Accepted July 22, 2011

${ }^{1}$ Approved for publication by the director of the Louisiana Agricultural Experimental Station as Manuscript Number 2011-2376118.

${ }^{2}$ Corresponding author: ssathivel@agcenter.lsu.edu
}

color than SYMSO. Although some slight differences were observed in the color and oxidation of SYMSO compared with SY, the study demonstrated that SY could be fortified with salmon oil.

Key words: marine fish oil, n-3, yogurt, microencapsulation

\section{INTRODUCTION}

Yogurt is a product made from heat-treated milk; it may also be homogenized before the addition of lactic acid bacteria (LAB) containing Lactobacillus bulgaricus and Streptococcus thermophilus (US FDA-DHHS, 2011). According to the USDA National Agricultural Statistics Service (USD-NASS, 2008), 739,355,563 kg of yogurt were produced in the United States in 1998, and by 2008, annual production had increased $120 \%$ to 3.59 billion lbs. In 2009, production of yogurt totaled a record high 3.83 billion lbs. and it was the 12 th straight year that yogurt production set a new record. According to Lempert (2009), yogurt was one of the 6 traditional snack categories that showed economic growth in 2009, while the NPD Group (2010), a market research company, announced recently that yogurt is among the top growing snack foods for children from 2 to $17 \mathrm{yr}$ of age. The production of yogurt with microencapsulated marine n-3 fatty acids may be an alternative for the increasing market of health-conscious consumers and may contribute to an increase in $\mathrm{n}-3$ consumption in the population. In a recent study, Blasbalg et al. (2011) quantified changes in the apparent consumption of n-3 and $n-6$ fatty acids in the United States during the 20th Century. The authors concluded that the increase in consumption of linoleic acid from soybean oil has decreased human tissue concentrations of eicosapentaenoic acid (EPA; 20:5 n-3) and docosahexaenoic acid (DHA; 22:6 n-3). It is known that the recommended intakes for n-3 fatty acids are not uniform (Whelan and Rust, 2006). In 2004, the International Society for the Study of Fatty Acids and Lipids (ISSFAL) recommended an intake of EPA and DHA of at least 500 mg/d (Cunnane et al., 2004).

Cardiovascular disease (CVD) is ranked as the number one killer in the United States. In 2010, the 
total direct and indirect costs of CVD and stroke in the United States were estimated to be $\$ 503.2$ billion (American Heart Association, 2010). Many scientific publications strongly suggest that regular consumption of significant amounts of polyunsaturated fatty acids (PUFA) rich in n-3 fatty acids can be highly effective in the prevention or treatment of CVD. Intake of PUFA is generally low in the diets of Western (developed) populations, and increased intake of these acids by supplementation of selected foods is recommended (Bauch et al., 2006). Salmon oil is a good source of PUFA, specifically EPA and DHA. Values reported by the USDA National Nutrient Database (USDA, 2009) indicate that $100 \mathrm{~g}$ of salmon oil contains 13.02 and $18.23 \mathrm{~g}$ of EPA and DHA, respectively.

A wide range of dairy and nondairy foods has been fortified with n-3 fatty acids. The main ways to deliver these fatty acids to foods are through direct addition of fish oil or algal oil and bio-delivery through meat and poultry products (Whelan and Rust, 2006). Most attempts to add DHA or EPA directly to foods have been unsuccessful because these fatty acids are unstable and rapidly give rise to a fishy odor and taste upon oxidation, making the food unpalatable. Microencapsulation is a process by which particles of sensitive materials are packed into a film of a coating material (Sathivel and Kramer, 2010), and this process could be used to decrease oxidation of salmon oil. The direct addition of microencapsulated salmon oil (MSO) to yogurt may not affect the original physical, chemical, and microbiological characteristics of the yogurt. Therefore, the objectives of this study were to develop a strawberry yogurt containing MSO (SYMSO; MSO at $2 \% \mathrm{wt} / \mathrm{vol}$ ) and evaluate its physical, chemical, and microbiological characteristics during 1 mo of storage.

\section{MATERIALS AND METHODS}

\section{Extraction and Purification of Oils}

Salmon oil was obtained from fresh red salmon (Oncorhynchus nerka) heads kept refrigerated at $4^{\circ} \mathrm{C}$. The salmon oil was extracted as described by Sathivel (2005), with modifications. The heads were weighed and ground using an industrial meat grinder (Northern Industrial, Burnsville, MN). The ground heads were cooked in 2-L beakers at $75^{\circ} \mathrm{C}$ for $30 \mathrm{~min}$ in a water bath (Lab-Line Instruments Inc., Melrose Park, IL) with constant electric stirring (model 5VB-C2, Eastern Mixers, Clinton, CT). The cooked, ground heads were centrifuged using a Beckman J2-HC centrifuge (GMI Inc., Ramsey, MN) at $7,957.6 \times g$ for $30 \mathrm{~min}$ at $4^{\circ} \mathrm{C}$. After centrifugation, unpurified salmon oil (USO) was collected and purified using chitosan, as described by
Huang and Sathivel (2010). Chitosan bears hydroxyl and amino groups, which are excellent functional groups for use adsorbents for a variety of complex compounds (Quignard et al., 2000). Huang and Sathivel (2010) reported that chitosan could be used as an adsorbent for removal of FFA and peroxides from unpurified salmon oil. Five percent (wt/vol) shrimp chitosan was added to the USO and the mixture was stirred for $1 \mathrm{~h}$ at room temperature. Then, the mixture was centrifuged $(23,385.6 \times g)$ for $25 \mathrm{~min}$ at $4^{\circ} \mathrm{C}$ and purified salmon oil (PSO) was collected. The PSO was characterized and stored in a blast freezer at $-20^{\circ} \mathrm{C}$ until use.

\section{Preparation of MSO}

Microencapsulated salmon oil was produced as described by $\mathrm{Pu}$ et al. (2011). A stable emulsion was prepared with a CPX-500 ultrasonic processor (Cole Parmer Instruments, Vernon Hills, IL) using the following ratio of components: $7 \%$ PSO: $22 \%$ gum arabic: $11 \%$ maltodextrin: $60 \%$ water. The emulsion was spray-dried in a FT80 tall form spray drier (Armfield Ltd., Ringwood, UK) at an inlet temperature of $180^{\circ} \mathrm{C}$ to produce MSO.

\section{Microencapsulation Efficiency and Encapsulation Yield}

The method described by Wanasundara and Shahidi (1995) was used to determine the microencapsulation efficiency of MSO. One hundred grams of MSO was dissolved in $500 \mathrm{~mL}$ of a $0.88 \%$ (wt/vol) $\mathrm{KCl}$ solution. A few crystals of tert-butylhydroquinone and $1.5 \mathrm{~L}$ of a 2:1 chloroform:methanol solution were added. The mixture was centrifuged at $23,385.6 \times g$ for 5 min at $4^{\circ} \mathrm{C}$ and transferred to a separatory funnel to separate the chloroform:methanol layer filtrate, which was collected in a round-bottomed flask for subsequent evaporation in a rotary evaporator (Buchi RE-121 Rotavapor, Flawil, Switzerland) at $40^{\circ} \mathrm{C}$ to reduce oxidation. The total oil (TO; \%) of MSO was calculated gravimetrically.

To extract the surface oil (SO) from MSO, $2 \mathrm{~g}$ of the microencapsulated powder was mixed with $10 \mathrm{~mL}$ of hexane for $10 \mathrm{~min}$. The mixture was filtered through Whatman 4 filter paper and washed with $4 \times 10 \mathrm{~mL}$ of hexane. The filter paper containing the washed sample was oven-dried (VWR model no. 1330FM, Sheldon Manufacturing Inc., Cornelius, OR) at $70^{\circ} \mathrm{C}$ until hexane evaporation was complete and a constant weight was obtained. The SO (\%) was calculated gravimetrically. The microencapsulation efficiency $(M E)$ was calculated as follows:

$$
M E=\frac{T O-S O}{T O} \times 100 .
$$


Encapsulation yield $(E Y)$ was determined using the following formula:

$$
E Y=\frac{O M(\mathrm{~g} / 100 \mathrm{~g})}{O E(\mathrm{~g} / 100 \mathrm{~g})},
$$

where $O M$ represents grams of total PSO in the $100 \mathrm{~g}$ of (dry weight) microcapsules and was calculated based on the TO (\%) and moisture content of MSO; OE represents the PSO in the emulsion and was calculated using the moisture content and PSO load of the emulsion described above.

\section{Peroxide Value, Anisidine Value, FFA, and Moisture of USO, PSO, and MSO}

The USO, PSO, and MSO samples were analyzed the day before being used for encapsulation and yogurt production, respectively. The peroxide value $(\mathbf{P V})$ and anisidine value (AV) were determined following American Oil Chemists Society (AOCS) Official Methods (AOCS, 1997). The acetic acid-chloroform method (AOCS method Cd 8-53) was used to determine the $\mathrm{PV}$. The PV of oils were reported in milliequivalents of peroxide per $1,000 \mathrm{~g}$ of oil. The AV of the oil was determined using AOCS method Cd 18-90. The total oxidation (TOTOX) was calculated based on the PV and AV using the following equation: $\mathrm{TOTOX}=2 \mathrm{PV}$ $+\mathrm{AV}$.

Free fatty acids were measured in USO, PSO, and MSO as described by AOCS method Ca 5a-40 (AOCS, 1997), with slight modifications. Two grams of the oil samples were mixed with $10 \mathrm{~mL}$ of heated and neutralized ethanol solution and $0.4 \mathrm{~mL}$ of phenolphthalein in a $125-\mathrm{mL}$ flask. The mixture was titrated using 0.1 $N \mathrm{NaOH}$ until a faint pink color was retained. The percentage FFA as oleic acid was calculated as follows:

$$
F F A(\%)=\frac{N a O H(\mathrm{~mL}) \times N \times 28.2}{\text { Mass }(\mathrm{g})},
$$

where $N=$ normality of $\mathrm{NaOH}$ and mass (g) refers to the mass of sample used. The moisture content of USO and PSO was determined using a Moisture Meter (CA-21 Moisture Meter, Cosa Instrument Corporation, Houston, TX). The moisture content of MSO was measured using a Moisture Analyzer Smart System 5 (CEM Corporation, Matthews, NC). Results are reported as percentage moisture.

\section{Preparation of Strawberry-Flavored Yogurt Containing MSO}

Strawberry-flavored yogurt with MSO (SYMSO) was produced by adding $2 \%$ MSO with the dry in- gredients before pasteurization and homogenization. Strawberry yogurt was produced in the Louisiana State University Department of Dairy Science Creamery. The dry ingredients, including MSO (Table 1), were incorporated into $2 \%$ fat milk in 18.9-L stainless steel containers before pasteurization. The mixture was homogenized at $3,447.4$ and $10,342.1 \mathrm{kPa}$ in the first and second stages, respectively, using a Gaulin 300 DJF 4 2PS homogenizer (APV Gaulin, Wilmington, MA) and then batch pasteurized for $30 \mathrm{~min}$ at $85 \pm 1^{\circ} \mathrm{C}$. The mixture was cooled to $43^{\circ} \mathrm{C}$ before addition of lactic cultures of Lactobacillus bulgaricus (LB-12, Chr. Hansen, Milwaukee, WI) and Streptococcus thermophilus (ST-M5, Chr. Hansen) at a rate of $1 \mathrm{~mL} / 3.78 \mathrm{~L}$ of milk each. Inoculated mixes were poured into 8-L stainless steel pots and placed in a low temperature incubator (model 815, Precision Scientific, Asheville, NC) at 43 $\pm 1^{\circ} \mathrm{C}$ until the $\mathrm{pH}$ reached 4.5. Samples were cooled immediately and stored at $4^{\circ} \mathrm{C}$ in a walk-in refrigerator. Strawberry with other natural flavors (Target Flavors Inc., Brookfield, CT), strawberry puree (Sensient Flavors, Fenton, MO), and FD\&C red 40 powder color (Sensient Colors) were added during the stirring procedure, after overnight aging of yogurt mixes. Sodium benzoate was used as a preservative. A control (SY) without MSO was produced and both yogurts were stored for $1 \mathrm{mo}$ at $4^{\circ} \mathrm{C}$. Yogurts were analyzed for fatty acid methyl esters (FAME), acidity, syneresis, thiobarbituric acid value (TBA), color, and LAB counts at d 1 and wk 1, 2, 3, and 4 .

\section{FAME of MSO, SYMSO, and SY}

Fatty acid methyl esters were measured by GC in MSO before use in yogurt production and at $\mathrm{d} 1$ and wk 4 for SYMSO and SY. Contents of FAME, expressed as a percentage of total FAME measured, in MSO and yogurts were determined using standard GC methods. Lipid was extracted from yogurt samples using a modified Folch extraction method in which $50 \mathrm{~g}$ of yogurt was homogenized in $1 \mathrm{~L}$ of $2: 1$ chloroform:methanol solution and then filtered through no. 4 filter paper. A $0.66 \% \mathrm{NaCl}$ solution $(200 \mathrm{~mL})$ was added before centrifugation at $649.6 \times g$ for $15 \mathrm{~min}$. The chloroform layer containing the lipids was evaporated using a rotary evaporator.

The FAME were prepared using the method described by Maxwell and Marmer (1983). Approximately $20 \mathrm{mg}$ of oil was methylated for analysis of fatty acid profile on a GC coupled to a flame ionization detector (Agilent Technologies Inc., Santa Clara, CA). Separation was made on a FAMEWAX $(30 \mathrm{~m} \times 0.32 \mathrm{~mm}$ i.d., 0.25 $\mathrm{mm}$ film) capillary column (Restek, Bellefonte, PA). Helium gas was the carrier at a constant flow rate of 
Table 1. Yogurt formulation in manufacture of strawberry yogurt (SY) and strawberry yogurt with microencapsulated salmon oil (SYMSO)

\begin{tabular}{llcc}
\hline Ingredient & $\begin{array}{l}\text { Addition } \\
\text { rate }\end{array}$ & $\begin{array}{c}\text { Control } \\
\text { (SY) }\end{array}$ & SYMSO \\
\hline 2\% fat milk, L & & 3.8 & 3.8 \\
Nonfat dry milk, g & $5 \%$ or $3 \%$ & 190.0 & 114.0 \\
Sugar, g & $5 \%$ & 190.0 & 190.0 \\
Microencapsulated salmon oil, g & $2 \%$ & - & 76.0 \\
Lactobacillus bulgaricus, mL & $1 \mathrm{~mL} / 3.8 \mathrm{~L}$ & 1.0 & 1.0 \\
Streptococcus thermophilus, mL & $1 \mathrm{~mL} / 3.8 \mathrm{~L}$ & 1.0 & 1.0 \\
Strawberry with other natural flavors, $\mathrm{mL}$ & $0.30 \%$ & 11.4 & 11.4 \\
Strawberry puree, g & $5 \%$ & 0.19 & 0.19 \\
Red 40 color, mL & $0.005 \%$ & 3.8 & 3.8 \\
Sodium benzoate, g & $0.10 \%$ & & \\
\hline
\end{tabular}

$2 \mathrm{~mL} / \mathrm{min}$. The inlet and detector temperatures were $250^{\circ} \mathrm{C}$ and $280^{\circ} \mathrm{C}$, respectively. The temperature program was as follows: initial temperature at $90^{\circ} \mathrm{C}$ with 8-min hold, increased to $175^{\circ} \mathrm{C}$ at $10^{\circ} \mathrm{C} / \mathrm{min}$ with $10-$ min hold, increased to $190^{\circ} \mathrm{C}$ at $4^{\circ} \mathrm{C} / \mathrm{min}$ with 10 -min hold, increased to $210^{\circ} \mathrm{C}$ at $5^{\circ} \mathrm{C} / \mathrm{min}$ with 5 -min hold, and then increased to $250^{\circ} \mathrm{C}$ at $20^{\circ} \mathrm{C} / \mathrm{min}$ with 8 -min hold. Standards used for identification of peaks were Supelco 37, Bacterial Acid Methyl Esters Mix, Marine Oil \#1, and Marine Oil \#3 (Supelco, Bellefonte, PA) and the internal standard used was C23:0.

\section{pH, Syneresis, TBA Value, and Color of SYMSO and SY}

The $\mathrm{pH}$ of the yogurts was measured using an EcoTestr $\mathrm{pH}$ tester (Eutech Instruments, Vernon Hills, IL) at about $8^{\circ} \mathrm{C}$. The meter was calibrated using commercial $\mathrm{pH} 4.00$ and 7.00 buffer solutions. The water-holding capacity of yogurt, expressed as syneresis, was determined using the method described by Cueva and Aryana (2008). The release of whey in the yogurt samples was measured by pouring $200 \mathrm{~g}$ of yogurt at $4^{\circ} \mathrm{C}$ onto fine cheesecloth placed on top of a funnel. The amount of whey collected in a graduated cylinder after $2 \mathrm{~h}$ was used as an index of syneresis. Analysis of TBA of SY and SYMSO samples was done following the procedure described by Hekmat and McMahon (1997). One gram of plain yogurt was weighed into a glass screw-top test tube; then, $9 \mathrm{~mL}$ of $15 \%$ (wt/vol) TCA and $0.375 \%$ (wt/vol) TBA reagent, and $0.25 \mathrm{~N} \mathrm{HCI}$ solution were added, mixed well, and heated in a boiling water bath for $15 \mathrm{~min}$. Samples were quickly cooled to room temperature with running water and centrifuged at 6,311.2 $\times g$ for $15 \mathrm{~min}$ at $20^{\circ} \mathrm{C}$. Absorbance was measured at $530 \mathrm{~nm}$ and the malonaldehyde (MDA) concentration was calculated with the extinction coefficient of 1.56 $\times 10^{5} M^{-1} \cdot \mathrm{cm}^{-1}$ using the following equation: $\mathrm{A} \lambda=\varepsilon$ $\times \mathrm{c} \times \mathrm{L}$, where $\mathrm{A} \lambda$ is absorbance, $\varepsilon$ is the extinction coefficient, $\mathrm{c}$ is the molar concentration expressed in moles of MDA per $\mathrm{kg}$ of yogurt, and $\mathrm{L}$ is the light path in centimeters. A Lab Scan XE spectrophotometer (Hunter Associates Laboratory Inc., Reston, VA) was used for color analysis of yogurts and MSO. Results are reported in $\mathrm{L}^{*}$ (lightness), $\mathrm{a}^{*}$ (red-green), and $\mathrm{b}^{*}$ (yellow-blue) values.

\section{LAB Microbial Counts}

Serial dilutions of yogurt were made using sterile de Man, Rogosa, and Sharpe broth for LAB (3M Microbiology, St. Paul, MN). Petrifilm aerobic count plates (3M Microbiology) were used for plating, and incubation was carried out in a Gaspak system at $35^{\circ} \mathrm{C}$ for $48 \mathrm{~h}$.

\section{Statistical Analysis}

Mean values and standard deviations of triplicate determinations were reported. Analysis of variance was carried out to determine the difference among treatments means (SAS version 8.2, SAS Institute Inc., Cary, NC) using the post hoc Tukey studentized range test.

\section{RESULTS AND DISCUSSION}

\section{$P V, A V, F F A$, and Moisture Contents of USO, PSO, and MSO}

Peroxide value is an indicator of initial lipid oxidation. The PV content of USO, PSO, and MSO was $10.13 \pm 0.7,5.16 \pm 0.05$, and $6.32 \pm 0.11 \mathrm{mEq} / \mathrm{kg}$, respectively. In the purification process, chitosan effectively adsorbed primary oxidation products. According to Gracey et al. (1999), oil with PV $<5 \mathrm{mEq} / \mathrm{kg}$ can be considered fresh oil or one in which hydroperoxides have degraded into secondary oxidation products, such as ketones and aldehydes. The secondary oxidation products were measured by AV. The AV of USO was low $(0.43 \pm 0.14)$ and no further reduction $(P>$ 
$0.05)$ occurred with chitosan purification. However, AV increased significantly $(P<0.05)$ after microencapsulation to $0.72 \pm 0.03$ (MSO). The TOTOX values (unitless; TOTOX $=2 \mathrm{PV}+\mathrm{AV}$ ) of USO, PSO, and MSO were calculated to be $20.7 \pm 1.26,10.88 \pm 0.1$, and $13.36 \pm 0.25$, respectively. Lipid oxidation in oilin-water emulsions has been studied and the interaction between lipid hydroperoxides located at the droplet surface and metals originating in the aqueous phase is the most common cause of oxidative instability (McClements and Decker, 2000). Kolanowski et al. (2006) reported that spray-drying results in higher PV and that oxidative stability of fish oil is not improved after the process. All oils had acceptable FFA values: 1.61 $\pm 0.19,0.59 \pm 0.02$, and $0.77 \pm 0.02 \%$ for USO, PSO, and MSO, respectively. Oils with FFA values $>3 \%$ are considered inedible (Gracey et al., 1999). The moisture content of USO and PSO was $0.18 \pm 0.01 \%$ and $0.16 \pm$ $0.01 \%$, respectively, and that of MSO was $2.44 \pm 0.12 \%$ (Table 2).

\section{SO, TO, Microencapsulation Efficiency, and Encapsulation Yield of MSO}

Measurements of TO $(13.9 \pm 0.45 \%)$ and SO (3.4 $\pm 0.18 \%$ ) content in MSO showed microencapsulation efficiency of $75.5 \pm 2.66 \%$. The SO content is an important attribute evaluated in spray-dried encapsulated oil powders because it influences oxidative stability, wettability, flowability, and color (Konstance et al., 1995). Microencapsulation efficiency reflects not only the nonencapsulated oil present on the surface of microcapsules but also the proportion of oil extracted from near the surface of the capsules (Rusli et al., 2006). Carbohydrates such as maltodextrin have typically been used as encapsulating agents (DeZarn, 1995). These materials are considered good encapsulating agents because they exhibit low viscosities at high solid contents and good solubility. Most of them also lack the interfacial properties required for high microencapsulation efficiency and are generally associated with other encapsulating materials such as proteins or gums (Yoshii et al., 2001). The values obtained in our study are comparable to those reported by McNamee et al. (2001), who reported microencapsulation efficiency of $72.7 \pm 1.3 \%$ for soybean oil microencapsulated using gum arabic and maltodextrin with a dextrose equivalent of 18.5. They suggest that this dextrose equivalent is the most suitable partial replacer for gum arabic as it is easily solubilized and bland in flavor, and as some preliminary work has shown, the dried encapsulates manufactured with this wall material are most rapidly reconstituted in water. The encapsulation yield calculated for this study was $81.5 \pm 0.47 \%$, indicating that gum arabic and maltodextrin were able to effectively encapsulate the PSO. Gum arabic stands out among other gums because of its excellent emulsification properties, which are attributed to the presence of a protein fraction in its structure (Dickinson et al., 2003). Results are shown in Table 2.

\section{FAME in MSO, SY, and SYMSO}

The fatty acid composition of lipids extracted from MSO, SY, and SYMSO are given in Table 3. Polyunsaturated fatty acids in MSO accounted for $32.7 \%$ of the fatty acids detected, and EPA and DHA were the predominant fatty acids, accounting for $62.6 \%$ of the total PUFA content. Initially, SY and SYMSO lipids contained 1.76 and $7.50 \%$ of total n-3 fatty acids, respectively. After 4 wk of storage, total n-3 fatty acids in SY and SYMSO lipids accounted for 1.47 and $5.82 \%$, respectively. The percentage reduction of total n-3 content after 4 wk of refrigerated storage was 16.5 and

Table 2. Physicochemical characteristics of unpurified (USO), purified (PSO), and microencapsulated (MSO) salmon oil

\begin{tabular}{|c|c|c|c|}
\hline \multirow[b]{2}{*}{ Item $^{1}$} & \multicolumn{3}{|c|}{ Salmon oil } \\
\hline & USO & $\mathrm{PSO}$ & MSO \\
\hline $\mathrm{PV}, \mathrm{mEq} / \mathrm{kg}$ of oil & $10.13 \pm 0.7$ & $5.14 \pm 0.04$ & $6.32 \pm 0.11$ \\
\hline $\mathrm{AV}$ & $0.43 \pm 0.14$ & $0.58 \pm 0.04$ & $0.72 \pm 0.03$ \\
\hline TOTOX & $20.7 \pm 1.26$ & $10.86 \pm 0.06$ & $13.36 \pm 0.25$ \\
\hline Free fatty acids, $\%$ & $1.61 \pm 0.19$ & $0.61 \pm 0.02$ & $0.77 \pm 0.02$ \\
\hline Moisture, \% & $0.18 \pm 0.01$ & $0.16 \pm 0.01$ & $2.44 \pm 0.12$ \\
\hline Total oil, \% & - & - & $13.86 \pm 0.45$ \\
\hline Surface oil, \% & - & - & $3.4 \pm 0.18$ \\
\hline Microencapsulation efficiency, \% & - & - & $75.49 \pm 2.66$ \\
\hline Encapsulation yield, \% & - & - & $81.53 \pm 0.47$ \\
\hline Color L* & - & - & $97.75 \pm 0.12$ \\
\hline Color a* & - & - & $1.37 \pm 0.17$ \\
\hline Color b* & - & - & $12.13 \pm 0.09$ \\
\hline
\end{tabular}


Table 3. Fatty acid methyl ester (FAME) composition of microencapsulated salmon oil (MSO), strawberry yogurt (SY), and SYMSO (strawberry yogurt with MSO) ${ }^{1}$

\begin{tabular}{|c|c|c|c|c|c|}
\hline \multirow{2}{*}{$\begin{array}{l}\text { FAME, } \% \text { of } \\
\text { total fatty acids }\end{array}$} & \multirow[b]{2}{*}{ MSO } & \multicolumn{2}{|c|}{ SY } & \multicolumn{2}{|c|}{ SYMSO } \\
\hline & & Initial & Wk 4 & Initial & Wk 4 \\
\hline C6:0 (caproic) & $-^{2}$ & $1.49^{\mathrm{a}}$ & $1.48^{\mathrm{a}}$ & $1.15^{\mathrm{a}}$ & $1.22^{\mathrm{a}}$ \\
\hline C8:0 (caprylic) & - & $1.06^{\mathrm{a}}$ & $1.04^{\mathrm{a}}$ & $0.82^{\mathrm{a}}$ & $0.89^{\mathrm{a}}$ \\
\hline $\mathrm{C} 10: 0$ (capric) & - & $2.67^{\mathrm{a}}$ & $2.56^{\mathrm{b}}$ & $2.08^{\mathrm{a}}$ & $2.24^{\mathrm{a}}$ \\
\hline C12:0 (lauric) & - & $3.29^{\mathrm{b}}$ & $3.45^{\mathrm{a}}$ & $2.57^{\mathrm{b}}$ & $2.76^{\mathrm{a}}$ \\
\hline C14:0 (myristic) & 4.29 & $11.04^{\mathrm{a}}$ & $10.99^{\mathrm{a}}$ & $9.92^{\mathrm{b}}$ & $10.23^{\mathrm{a}}$ \\
\hline C15:0 (pentadecanoic) & 0.63 & $1.12^{\mathrm{a}}$ & $1.13^{\mathrm{a}}$ & $0.98^{\mathrm{a}}$ & $1.02^{\mathrm{a}}$ \\
\hline C16:0 (palmitic) & 14.05 & $30.03^{\mathrm{a}}$ & $30.03^{\mathrm{a}}$ & $26.7^{\mathrm{a}}$ & $27.28^{\mathrm{a}}$ \\
\hline C16:1n-7 (palmitoleic) & 4.34 & $1.68^{\mathrm{a}}$ & $1.59^{\mathrm{b}}$ & $2.61^{\mathrm{a}}$ & $2.34^{\mathrm{b}}$ \\
\hline C18:0 (stearic) & 2.47 & $14.95^{\mathrm{a}}$ & $14.92^{\mathrm{a}}$ & $12.19^{\mathrm{b}}$ & $12.73^{\mathrm{a}}$ \\
\hline C18:1n-9 (oleic) & 16.85 & $23.59^{\mathrm{a}}$ & $23.51^{\mathrm{a}}$ & $22.11^{\mathrm{a}}$ & $22.37^{\mathrm{a}}$ \\
\hline C18:1n-7 (vaccenic) & 3.19 & $3.07^{\mathrm{b}}$ & $3.18^{\mathrm{a}}$ & $2.97^{\mathrm{a}}$ & $2.94^{\mathrm{a}}$ \\
\hline C18:2n-6 (linoleic) & 2.09 & $4.32^{\mathrm{a}}$ & $4.44^{\mathrm{a}}$ & $3.98^{\mathrm{a}}$ & $3.96^{\mathrm{a}}$ \\
\hline C18:3n-3 ( $\alpha$-linolenic) & 1.67 & $0.86^{\mathrm{a}}$ & $0.59^{\mathrm{b}}$ & $0.81^{\mathrm{a}}$ & $0.77^{\mathrm{b}}$ \\
\hline C18:4n-3 (octadecatetraenoic) & 3.10 & $0.9^{\mathrm{a}}$ & $0.88^{\mathrm{a}}$ & $0.79^{\mathrm{a}}$ & $0.73^{\mathrm{a}}$ \\
\hline C20:1n-11 (gadoleic) & 7.56 & - & - & $1.82^{\mathrm{a}}$ & $1.69^{\mathrm{b}}$ \\
\hline C20:1n-9 (eicosenoic) & 3.27 & - & - & $0.84^{\mathrm{a}}$ & $0.82^{\mathrm{a}}$ \\
\hline C20:4n-3 (eicosatetraenoic) & 1.89 & - & - & - & - \\
\hline C20:5n-3 (eicosapentaenoic) & 10.24 & - & - & $2.9^{\mathrm{a}}$ & $2.11^{\mathrm{a}}$ \\
\hline C22:1n-11 (cetoleic) & 8.31 & - & - & $1.77^{\mathrm{a}}$ & $1.66^{\mathrm{b}}$ \\
\hline C22:5n-3 (docosapentaenoic) & 2.33 & - & - & $0.63^{\mathrm{a}}$ & $0.49^{\mathrm{b}}$ \\
\hline C22:6n-3 (docosahexaenoic) & 10.24 & - & - & $2.37^{\mathrm{a}}$ & $1.72^{\mathrm{b}}$ \\
\hline Saturated fatty acids & 21.44 & $65.65^{\mathrm{a}}$ & $65.60^{\mathrm{a}}$ & $56.41^{\mathrm{a}}$ & $58.37^{\mathrm{a}}$ \\
\hline Monounsaturated fatty acids & 45.83 & $28.34^{\mathrm{a}}$ & $28.28^{\mathrm{a}}$ & $32.12^{\mathrm{a}}$ & $31.82^{\mathrm{a}}$ \\
\hline Polyunsaturated fatty acids & 32.72 & $6.08^{\mathrm{a}}$ & $5.91^{\mathrm{b}}$ & $11.48^{\mathrm{a}}$ & $9.78^{\mathrm{b}}$ \\
\hline Total n-3 & 29.48 & $1.76^{\mathrm{a}}$ & $1.47^{\mathrm{b}}$ & $7.50^{\mathrm{a}}$ & $5.82^{\mathrm{b}}$ \\
\hline Total n- 6 & 2.75 & $4.32^{\mathrm{b}}$ & $4.44^{\mathrm{a}}$ & $3.98^{\mathrm{a}}$ & $3.96^{\mathrm{a}}$ \\
\hline
\end{tabular}

a,b Different superscripts indicate a statistical difference $(P<0.05)$ between initial and wk-4 means of SY or SYMSO, separately.

${ }^{1}$ Values are means of triplicate determinations and rows with values for samples of less than $1 \%$ in all columns are not included.

${ }^{2}$ Not detected.

$22.4 \%$ for SY and SYMSO, respectively. Among PUFA in SYMSO lipids, EPA and DHA were the predominant fatty acids and neither was detected in SY. Considering that SYMSO had a fat content (estimated by the Babcock method) of $2.0 \pm 0.2 \%$, a serving $(200 \mathrm{~g})$ of SYMSO at d 1 may contain $0.21 \pm 0.01 \mathrm{~g}$ of EPA + DHA. Typical recommendations are 0.3 to $0.5 \mathrm{~g} / \mathrm{d}$ of EPA + DHA (Institute of Medicine, 2002) and patients with CVD are encouraged to increase their consumption of EPA and DHA to approximately $1 \mathrm{~g} / \mathrm{d}$ (KrisEtherton et al., 2002). The intake of total n-3 fatty acids in the United States is approximately $1.6 \mathrm{~g} / \mathrm{d}$ (Kris-Etherton et al., 2000). Of this, $\alpha$-linolenic acid accounts for approximately $1.4 \mathrm{~g} / \mathrm{d}$, and only 0.1 to 0.2 $\mathrm{g} / \mathrm{d}$ comes from EPA and DHA (USDA, 2002). Moreover, the mean intake of $\alpha$-linoleic acid, EPA, DHA, and total marine n-3 fatty acids in US women $54.6 \pm$ $7.0 \mathrm{yr}$ old, was reported to be $1.11,0.04,0.12$, and 0.18 g/d, respectively (Djoussé et al., 2011).

\section{pH of SY and SYMSO}

Fortification of strawberry yogurt with MFO had no significant effect on yogurt $\mathrm{pH}$. The initial $\mathrm{pH}$ of $\mathrm{SY}$ and SYMSO was $4.5 \pm 0.0$, which is very similar to the $\mathrm{pH}$ values of SY $(4.4 \pm 0.0)$ and SYMSO $(4.4 \pm 0.0)$ measured after $4 \mathrm{wk}$ of refrigerated storage. This is in accordance with results reported by Serra et al. (2009) in which titratable acidity increased slightly after 28 $\mathrm{d}$ of cold storage of set and stirred yogurts. This is a result of the persistent metabolic activity of starters, which has also been called postacidification (Beal et al., 1999). Ott et al. (2000) highlighted that $\mathrm{pH}$ correlates very well with most of the flavor attributes of yogurt. Moreover, they concluded that the intensity of yogurt flavor perception is driven by $\mathrm{pH}$.

\section{Syneresis of SY and SYMSO}

Spontaneous syneresis is the expulsion of whey from yogurts because of structural rearrangements in the gel network (Serra et al., 2009). Structure rearrangements in yogurt have been previously reported by Hassan et al. (1995), Lucey et al. (1998), and Singh and Muthukumarappan (2008). Syneresis results are reported in Table 4. A slight, but not significant $(P>0.05)$, trend to increasing syneresis was observed in SY and SYMSO during storage. The mean values for syneresis in SY 
ranged from $43.2 \pm 7.02$ initially to $48.4 \pm 3.19 \mathrm{in} \mathrm{wk}$ 4. A similar trend was observed in SYMSO, in which syneresis increased from $40.1 \pm 2.08$ to $45.2 \pm 1.73$ from d 1 to wk 4, respectively. No significant differences were found in syneresis with fortification of MSO versus no addition (SY) throughout the storage study, except in wk 2, when syneresis was significantly higher $(P<0.05)$ in SY. This may be indicative of a similarity in the nature of the bonds involved in the gel structure formation of both yogurt samples. Syneresis produced by funnel drainage does not represent the usual breakage of the yogurt matrix, but reflects the capability of the whole gel structure to retain water.

\section{TBA Values of SY and SYMSO}

Polyunsaturated fatty acids, as well as dairy products, are known to be susceptible to oxidation upon processing and storage, resulting in development of rancid off-flavors and taste. The lipid oxidation of SY and SYMSO during storage was evaluated by TBA analysis and the results are presented in Table 4. The results showed that lipid oxidation in yogurt was significantly increased in yogurts stored for 4 wk compared with initial values. The initial TBA values for SY and SYMSO were $0.05 \pm 0.02$ and $0.12 \pm 0.01 \mathrm{~mol}$ of MDA $/ \mathrm{kg}$ of yogurt, respectively. The TBA values increased proportionately to storage period and were different $(P<0.05)$ between SY and SYMSO in all the storage periods evaluated. By wk 4, TBA in SY underwent a 2.0-fold increase to $0.1 \pm 0.01$, whereas TBA in SYMSO underwent a 2.2-fold increase to $0.26 \pm 0.01$ mol of MDA $/ \mathrm{kg}$ of yogurt. Al-Rowaily (2008) studied the effect of processing methods and refrigerated storage of set and strained yogurt on lipid oxidation. The results indicated that lipid oxidation was significantly increased by milk batch pasteurization at 85 to $90^{\circ} \mathrm{C}$ for $2 \mathrm{~min}$. Refrigerated storage of set yogurt for $7 \mathrm{~d}$ and strained yogurt for $15 \mathrm{~d}$ caused a significant difference in peroxide, anisidine, and TOTOX values. Lee et al. (2007) reported a slow TBA absorbance increase from 0.083 to 0.10 over the initial $6 \mathrm{~d}$ of storage of evening primrose oil (EPO)-enriched yogurt, followed by a dramatic increase up to 0.165 after $15 \mathrm{~d}$. Evening primrose oil is of special interest due to its high PUFA content. Overall, the results of the Lee et al. (2007) study indicated that lipid oxidation proceeded more rapidly in yogurt with EPO than in that without $\mathrm{EPO}$, in accordance with the trend observed in our study with SY and SYMSO. Furthermore, Hekmat and McMahon (1997) studied the overall effect of $30 \mathrm{~d}$ of storage on yogurt chemical oxidation, as measured by the TBA test. Low-fat yogurt exhibited a tendency toward increased chemical oxidation during storage

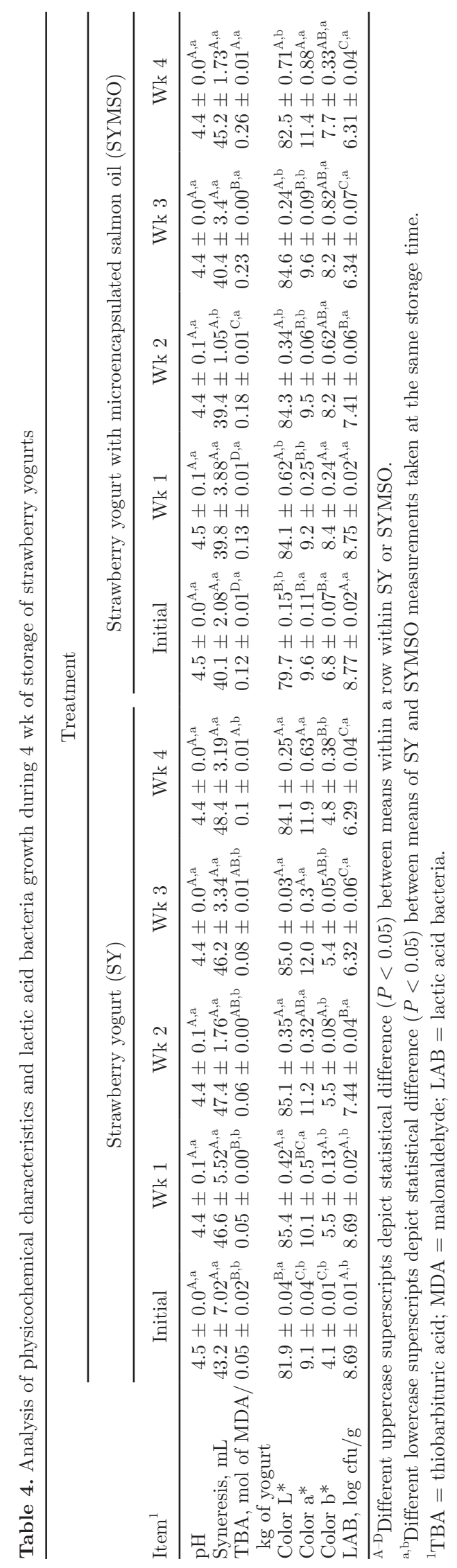


up to $30 \mathrm{~d}$. Oxidation can cause rancidity and thus negatively affect the sensory properties of taste and aroma (Kolanowski et al., 1999). Inoue et al. (1998) did not report any significant effect of malonaldehyde concentrations ranging from 5 to $10 \times 10^{-5} \mathrm{mmol} / \mathrm{mL}$ on the sensory evaluation of frozen yogurt during $6 \mathrm{mo}$ of storage. The results in our study are well below TBA thresholds for rancid odor detection in meats, which have been estimated to be 0.5 to $1 \mathrm{mg} / \mathrm{kg}$ (Tarladgis et al., 1960) and $2 \mathrm{mg} / \mathrm{kg}$ (Greene and Cumuze, 1981). To the best of our knowledge, a threshold limit for dairy products is not available in literature.

\section{Color of MSO, SY, and SYMSO}

The $\mathrm{L}^{*}(97.75 \pm 0.12), \mathrm{a}^{*}(1.37 \pm 0.17)$, and $\mathrm{b}^{*}$ $(12.13 \pm 0.09)$ values of MSO are shown in Table 2 and those for SY and SYMSO are reported in Table 4. The initial $L^{*}$ (lightness) value for SY $(81.9 \pm 0.04)$ was slightly but significantly higher $(P<0.05)$ than that for SYMSO $(79.7 \pm 0.15)$. The $L^{*}$ values showed an increase after the first week of storage and SY values were higher than SYMSO during the entire study. An increase in $\mathrm{a}^{*}$ values was observed during $30 \mathrm{~d}$ of storage, from $9.1 \pm 0.04$ to $11.9 \pm 0.63$ in $\mathrm{SY}$ and from $9.6 \pm 0.11$ to $11.4 \pm 0.88$ in SYMSO, indicating an increase in the redness of the yogurts. Gel stirring and acidity changes in yogurt detected during refrigerated storage may be the cause of changes in $a^{*}$ values because they may cause tissue structure changes that result in leakage of natural pigments (carotenoids) to the yogurt matrix. The control yogurt (initial $\mathrm{b}^{*}=4.1$ \pm 0.01 ) was less yellow than SYMSO (initial $b^{*}=6.8$ $\pm 0.07)$. The significantly $(P<0.05)$ greater yellowness of SYMSO can be attributed to the addition of MSO, which has a yellowish color imparted by the nonencapsulated salmon oil. To determine if color differences between samples could be detected by the naked eye, 12 untrained panelists were selected from among the staff of the Louisiana State University Department of Food Science. Panelists were requested to evaluate the appearance of the samples, which were identified with random 3-digit codes. No differences in color were detected in the appearance sensory assessment due to addition of $2 \%$ MSO to the SY formulation (data not shown).

\section{LAB Counts of SY and SYMSO}

Addition of MSO resulted in slightly higher $(P<$ $0.05)$ initial LAB counts in SYMSO. A decrease in viable counts of LAB was observed during storage of SY and SYMSO, which indicates low stability of the starter culture during shelf life. The initial counts of LAB were $8.69 \pm 0.01$ and $8.77 \pm 0.02 \log \mathrm{cfu} / \mathrm{g}$; by wk 4 , the counts decreased to $6.29 \pm 0.04$ and $6.31 \pm 0.04 \log$ $\mathrm{cfu} / \mathrm{g}$ in SY and SYMSO, respectively (Table 4). In a study concerning microbiological evolution of LAB during the shelf life of yogurt, Rotar et al. (2007) reported that the initial concentration of LAB was between $10^{6}$ and $10^{7} \mathrm{cfu} / \mathrm{g}$ (a concentration considered good for the yogurt to fortify its nutritional value to consumers), but decreased to around $10^{4} \mathrm{cfu} / \mathrm{g}$ (inadequate level) toward the end of the shelf-life study. Dave and Shah (1996) reported that viable counts of starter culture bacteria in yogurt increased and then declined during a 28-d refrigerated storage study. Lee et al. (2007) reported a decreasing trend in mean microbial counts during 15 d of refrigerated storage of yogurt enriched with EPO.

\section{CONCLUSIONS}

In the purification process, chitosan effectively adsorbed primary oxidation products but did not lower secondary oxidation products as measured by AV. The total oxidation of salmon oil was significantly increased after the emulsification and spray-drying process. The addition of MSO (2\% wt/vol) to SY had no effect on the $\mathrm{pH}$ and syneresis of SYMSO. No significant differences were observed in LAB counts of SY and SYMSO; however, a decrease in LAB counts was observed during the storage of yogurts. Eicosapentaenoic acid and DHA were the predominant PUFA in MSO and they were abundant in SYMSO. Oxidation of SY and SYMSO (TBA values) increased as storage time increased; however, the low concentrations of malonaldehyde may not have had significant effects on sensory perception during 4 wk of storage. The addition of MSO to yogurt did not greatly modify $\mathrm{pH}$, color, or water-holding capacity characteristics of SY. The results from our study demonstrate that SYMSO can be produced by direct addition of MSO before homogenization and pasteurization. To determine the potential for commercialization of strawberry yogurt fortified with microencapsulated fish oil, further research is suggested to evaluate its sensory quality and correlation to physicochemical characteristics.

\section{REFERENCES}

Al-Rowaily, M. A. 2008. Effect of heating treatments, processing methods and refrigerated storage of milk and some dairy products on lipids oxidation. Pakistan J. Nutr. 7:118-125.

American Heart Association. 2010. Heart Disease and Stroke Statistics-2010 Update. American Heart Association, Dallas, TX. 
AOCS. 1997. Official Methods and Recommended Practices of the American Oil Chemists Society. AOCS, Champaign, IL.

Bauch, A., O. Lindtner, G. Mensink, and B. Niemann. 2006. Dietary intake and sources of long chain n-3 PUFAs in German adults. Eur. J. Clin. Nutr. 60:810-812.

Beal, C., J. Skokanova, E. Latrille, N. Martin, and G. Corrieu. 1999 Combined effects of culture conditions and storage time on acidification and viscosity of stirred yogurt. J. Dairy Sci. 82:673-681.

Blasbalg, T. L., J. R. Hibbeln, C. E. Ramsden, S. F. Majchrzak, and R. R. Rawlings. 2011. Changes in consumption of omega-3 and omega-6 fatty acids in the United States during the 20th century. Am. J. Clin. Nutr. 93:950-962. doi:10.3945/ajen.110.006643.

Cueva, O., and K. J. Aryana. 2008. Quality attributes of a heart healthy yogurt. Lebenson. Wiss. Technol. 41:537-544.

Cunnane, S., C. A. Drevon, W. Harris, A. Sinclair, and A. Spector. 2004. Recommendations for intakes of polyunsaturated fatty acids in healthy adults. ISSFAL Newsl. 11:12-25.

Dave, R. I., and N. R. Shah. 1996. Effect of level of starter culture on viability of yoghurt and probiotic bacteria in yoghurts. 29th AIFST Convention, Gold Coast, Australia.

DeZarn, T. G. 1995. Food ingredients encapsulation: An overview. Pages 74-86 in Encapsulation and Controlled Release of Food Ingredients, S. J. Risch and G. A. Reineccius, ed. American Chemical Society symposium series Vol. 590. American Chemical Society, Washington, DC

Dickinson, E., S. Radford, and M. Golding. 2003. Stability and rheology of emulsions containing sodium caseinate: Combined effects of ionic calcium and non-ionic surfactant. Food Hydrocoll. 17:211220

Djoussé, L., J. M. Gaziano, J. E. Buring, and I. M. Lee. 2011. Dietary omega- 3 fatty acids and fish consumption and risk of type 2 diabetes. Am. J. Clin. Nutr. 93:143-150.

Gracey, J. F., D. S. Collins, and R. Huey. 1999. Fat Rancidity. Page 407 in Meat Hygiene. 10th ed. Harcourt Brace and Co. Ltd., London, UK

Greene, B. E., and T. H. Cumuze. 1981. Relationship between TBA numbers and inexperienced panelists assessments of oxidized flavor in cooked beef. J. Food Sci. 47:52-58.

Hassan, A. N., J. F. Frank, K. A. Schmidt, and S. I. Shalabi. 1995. Formation of yogurt microstructure and three dimensional visualization as determined by confocal scanning laser microscopy. J. Dairy Sci. 78:2629-2636.

Hekmat, S., and D. J. McMahon. 1997. Manufacture and quality of iron-fortified yogurt. J. Dairy Sci. 80:3114-3122.

Huang, J., and S. Sathivel. 2010. Purifying salmon oil using adsorption, neutralization, and a combined neutralization and adsorption process. J. Food Eng. 96:51-58.

Inoue, K., K. Shiota, and T. Ito. 1998. Preparation and properties of ice cream type frozen yoghurt. Int. J. Dairy Technol. 51:44-50.

Institute of Medicine. 2002. Dietary Reference Intakes for Energy and Macronutrients. Consensus Report 2002. IOM, Washington, DC.

Kolanowski, W., F. Swiderski, and S. Berger. 1999. Possibilities of fish oil application for food products enrichment with omega-3 PUFA. Int. J. Food Sci. Nutr. 50:39-49.

Kolanowski, W., M. Ziolkowski, J. Weißrodt, B. Kunz, and G. Laufenberg. 2006. Microencapsulation of fish oil by spray drying - Impact on oxidative stability. Part 1. Eur. Food Res. Technol. 222:336342 .

Konstance, R. P., C. I. Onwulata, and V. H. Holsinger. 1995. Flow properties of spray dried encapsulated butter oil. J. Food Sci 60:841-844.

Kris-Etherton, P. M., W. S. Harris, and L. J. Appel. 2002. Fish consumption, fish oil, omega-3 fatty acids, and cardiovascular disease. Circulation 106:2747-2757.

Kris-Etherton, P. M., D. S. Taylor, S. Yu-Poth, P. Huth, K. Moriarty, V. Fishell, R. L. Hargrove, G. Zhao, and T. D. Etherton. 2000 Polyunsaturated fatty acids in the food chain in the United States. Am. J. Clin. Nutr. 71(Suppl.):179S-188S
Lee, S. J., J. Hwang, S. Lee, J. Ahn, and H. Kwak. 2007. Property changes and cholesterol-lowering effects in evening primrose oilenriched and cholesterol-reduced yogurt. Int. J. Dairy Technol. 60:22-30.

Lempert, P. 2009. Few alternative snacks on the rise. Facts, Figures and the Future, June. Accessed Jan. 18, 2011. http://app.subscribermail.com/dspcd.cfm?ec=f2d5b481e13e4427acb0e5ce4695fe7 8\&email $=0$.

Lucey, J. A., C. T. Teo, P. A. Munro, and H. Singh. 1998. Microstructure, permeability, and appearance of acid gels made from heated skim milk. Food Hydrocoll. 12:159-165.

Maxwell, R. J., and W. N. Marmer. 1983. Systemic protocol for accumulation of fatty acid data from multiple tissue samples: Tissue handling, lipid extraction and class separation, and capillary gas chromatographic analysis. Lipids 18:453-459.

McClements, D. J., and E. A. Decker. 2000. Lipid oxidation in oil-inwater emulsions: Impact of molecular environment on chemical reactions in heterogeneous food systems. J. Food Sci. 65:1270-1282.

McNamee, B. F., E. D. O'Riordan, and M. O'Sullivan. 2001. Effect of partial replacement of gum arabic with carbohydrates on its microencapsulation properties. J. Agric. Food Chem. 49:3385-3388.

NPD Group. 2010. Yogurt, potato chips, and fresh fruit among top growing snack foods for kids, 2-17. SnackTrack Press Release. Accessed Jan. 18, 2011. http://www.npd.com/press/releases/ press 100511.html.

Ott, A., A. Hugi, M. Baumgartner, and A. Chaintreau. 2000. Sensory investigation of yogurt flavor perception: Mutual influence of volatiles and acidity. J. Agric. Food Chem. 48:441-450.

Pu, J., J. D. Bankston, and S. Sathivel. 2011. Developing microencapsulated flaxseed oil containing shrimp (Litopenaeus setiferus) astaxanthin using a pilot scale spray dryer. Biosystems Eng. 108:121-131.

Quignard, F., A. Choplin, and A. Domard. 2000. Chitosan: A natural polymeric support of catalysts for the synthesis of fine chemicals. Langmuir 16:9106-9108.

Rotar, M. A., C. Semeniuc, S. Apostu, R. Suharischi, C. Muresan, C. Modoran, C. Laslo, C. Guş, and M. Culea. 2007. Researched concerning microbiological evolution of lactic acid bacteria to yoghurt storage during shelf life. J. Agroalim. Process. Technol. XIII: $135-138$

Rusli, J. K., L. Sanguansri, and M. A. Augustin. 2006. Stabilization of oils by microencapsulation with heated protein-glucose syrup mixtures. J. Am. Oil Chem. Soc. 83:965-972.

Sathivel, S. 2005. Thermal and flow properties of oils from salmon heads. J. Am. Oil Chem. Soc. 82:147-152.

Sathivel, S., and D. E. Kramer. 2010. Chapter 33: Microencapsulation, nanoencapsulation, edible film, and coatings applications in seafood processing. Pages 414-422 in Seafood Quality, Safety, and Health Effects. C. Alasalvar, K. Miyashita, F. Shahidi, and U. Wanasundara, ed. Blackwell Publishing Ltd., Oxford, UK.

Serra, M., A. J. Trujillo, B. Guamis, and V. Ferragut. 2009. Evaluation of physical properties during storage of set and stirred yogurts made from ultra-high pressure homogenization-treated milk. Food Hydrocoll. 23:82-91.

Singh, G., and K. Muthukumarappan. 2008. Influence of calcium fortification on sensory, physical and rheological characteristics of fruit yogurt. Lebenson. Wiss. Technol. 41:1145-1152.

Tarladgis, B. J., B. M. Watts, M. T. Younathan, and L. R. Dugan. 1960. A distillation method of quantitative determination of malonaldehyde in rancid foods. J. Am. Oil Chem. Soc. 37:44-48.

USDA. 2009. National Nutrient Database for Standard Reference: Fish oil, salmon. Nutrient values and weights for edible portion. Accessed Aug. 11, 2010. http://www.nal.usda.gov/fnic/foodcomp/ cgi-bin/list_nut_edit.pl.

USDA-ERS. 2002. Food consumption (per capita) data system. Economic Research Service. Accessed May 2010. http://www.ers.usda. gov/data/foodconsumption. 
USDA-NASS. 2008. Plain and Flavored Yogurt U.S. Production Quick Stats 1998-2008. Accessed Jan. 18, 2011.http://www.nass.usda. gov/QuickStats/PullData_US.jsp.

US FDA-DHHS. 2011. 21CFR131.203: Low fat yogurt. http://www accessdata.fda.gov/scripts/cdrh/cfdocs/cfcfr/CFRSearch.cfm? fr $=131.203$

Wanasundara, U., and F. Shahidi. 1995. Storage stability of microencapsulated seal blubber oil. J. Food Lipids 2:73-86.
Whelan, J., and C. Rust. 2006. Innovative dietary sources of n-3 fatty acids. Annu. Rev. Nutr. 26:75-103.

Yoshii, H., A. Soottitantawat, X. Liu, T. Atarashi, T. Furuta, S. Aishima, M. Ohgawara, and P. Linko. 2001. Flavor release from spray-dried maltodextrin/gum arabic or soy matrices as a function of storage relative humidity. Innov. Food Sci. Emerg. Technol. 2:55-61. 